\title{
Incidence of, predictors for, and mortality associated with malignant ventricular arrhythmias in non-ST elevation myocardial infarction patients.
}

\author{
Shuchita Gupta, MD \\ Albert Einstein Medical Center \\ Gregg S. Pressman \\ Einstein Medical Center \\ Vincent M. Figueredo, M.D. \\ Thomas Jefferson University
}

Follow this and additional works at: https://jdc.jefferson.edu/cardiologyfp

Part of the Cardiology Commons

\section{Let us know how access to this document benefits you}

\section{Recommended Citation}

Gupta, MD, Shuchita; Pressman, Gregg S.; and Figueredo, M.D., Vincent M., "Incidence of, predictors for, and mortality associated with malignant ventricular arrhythmias in non-ST elevation myocardial infarction patients." (2010). Division of Cardiology Faculty Papers. Paper 22.

https://jdc.jefferson.edu/cardiologyfp/22

This Article is brought to you for free and open access by the Jefferson Digital Commons. The Jefferson Digital Commons is a service of Thomas Jefferson University's Center for Teaching and Learning (CTL). The Commons is a showcase for Jefferson books and journals, peer-reviewed scholarly publications, unique historical collections from the University archives, and teaching tools. The Jefferson Digital Commons allows researchers and interested readers anywhere in the world to learn about and keep up to date with Jefferson scholarship. This article has been accepted for inclusion in Division of Cardiology Faculty Papers by an authorized administrator of the Jefferson Digital Commons. For more information, please contact: JeffersonDigitalCommons@jefferson.edu. 


\title{
Incidence of, Predictors for, and Mortality Associated with Malignant Ventricular Arrhythmias in Non-ST Elevation Myocardial Infarction Patients
}

\author{
Shuchita Gupta MD \\ Albert Einstein Medical Center \\ Gregg S. Pressman MD \\ Jefferson Medical College \\ Vincent M. Figueredo MD \\ Jefferson Medical College, FigueredoV@einstein.edu
}

Follow this and additional works at: http://jdc.jefferson.edu/internalfp

Part of the Medicine and Health Sciences Commons

\section{Recommended Citation}

Gupta MD, Shuchita; Pressman MD, Gregg S.; and Figueredo MD, Vincent M., "Incidence of, Predictors for, and Mortality Associated with Malignant Ventricular Arrhythmias in Non-ST Elevation Myocardial Infarction Patients" (2010). Department of Internal Medicine Faculty Papers \& Presentations. Paper 4.

http://jdc.jefferson.edu/internalfp/4

This Article is brought to you for free and open access by the Jefferson Digital Commons. The Jefferson Digital Commons is a service of Thomas Jefferson University's Academic \& Instructional Support \& Resources Department (AISR). The Commons is a showcase for Jefferson books and journals, peer-reviewed scholarly publications, unique historical collections from the University archives, and teaching tools. The Jefferson Digital Commons allows researchers and interested readers anywhere in the world to learn about and keep up to date with Jefferson scholarship. This article has been accepted for inclusion in Department of Internal Medicine Faculty Papers \& Presentations by an authorized administrator of the Jefferson Digital Commons. For more information, please contact: JeffersonDigitalCommons@jefferson.edu. 


\title{
As submitted to:
}

\section{Coronary Artery Disease}

\author{
And later published as:
}

"Incidence of, Predictors for, and Mortality Associated with

Malignant Ventricular Arrhythmias in Non-ST Elevation

Myocardial Infarction Patients"

\section{Volume 21, Issue 8, December 2010, Pages 460-465 \\ DOI: 10.1097/MCA.0b013e32834022fa}

Shuchita Gupta MD ${ }^{\mathrm{a}}$, Gregg S. Pressman MD ${ }^{\mathrm{b}}$, Vincent M. Figueredo MD

${ }^{a}$ Department of Internal Medicine, Albert Einstein Medical Center, ${ }^{b}$ Einstein Center for Heart and Vascular Health, Albert Einstein Medical Center and Jefferson Medical College, Philadelphia, PA.

Running Head: Ventricular arrhythmias in non-ST elevation myocardial infarction Keywords: ventricular arrhythmias, ventricular tachycardia, ventricular fibrillation, nonST elevation myocardial infarction, cardiovascular mortality

List of Support/Grant Information: None 
Corresponding Author: $\quad$ Vincent M. Figueredo, MD, Einstein Center for Heart and Vascular Health Albert Einstein Medical Center Levy Building 3232 5401 Old York Road, Philadelphia, PA 19141 Telephone: 2154568991

Fax: 2154563533

E-mail: figueredov@einstein.edu

\section{ABSTRACT}

Background: The incidence of non-ST elevation myocardial infarction (NSTEMI) is increasing. While life-threatening ventricular arrhythmias have been well-documented in patients with ST elevation myocardial infarction (STEMI), their incidence and importance in NSTEMI have not been examined in similar detail. We examined the incidence, predictors and mortality rates of ventricular arrhythmias in a cohort of NSTEMI patients undergoing an early invasive strategy.

Methods: Consecutive patients admitted with NSTEMI who underwent cardiac catheterization within 48 hours of admission were identified via chart review. Presence and type of ventricular arrhythmias and 30 day mortality were recorded. Malignant arrhythmias were defined as sustained ventricular tachycardia (VT; >100 beats/minute lasting $>30$ seconds) or fibrillation (VF). Clinical risk factors, laboratory values, findings on electrocardiogram, echocardiogram, cardiac catheterization, and revascularization procedure data were recorded.

Results: VT/VF occurred in $21(7.6 \%)$ of 277 NSTEMI patients. Sixty percent of these events occurred within the first 48 hours following hospital admission, with a median 
occurrence at 72 hours. Twelve $(4.3 \%)$ required defibrillation. Troponin levels were higher and left ventricular ejection fraction lower in the VT/VF group. Multivariable analysis also identified the presence of left bundle branch block and need for urgent coronary artery bypass grafting as significant predictors of malignant ventricular arrhythmias. Thirty day mortality was significantly higher in NSTEMI patients with malignant ventricular arrhythmias than without (38 versus 3\%; $<<0.001$ ).

Conclusion: Despite early invasive strategy, malignant ventricular arrhythmias are frequent in NSTEMI patients and are associated with increased 30 day mortality. 
Acute myocardial infarction patients are prone to developing life-threatening ventricular arrhythmias in the early phase of their event. Ischemia has a rapid and profound effect on the electrophysiological properties of the myocyte. Changes in the resting membrane potential and ionic fluxes during the action potential lead to alterations in conduction, refractoriness, and automaticity of cardiac muscle cells, all of which contribute to the occurrence of arrhythmias in these patients ${ }^{1,2}$. The incidence of ventricular arrhythmias in acute myocardial infarction is reported to be between 2 and $20 \% \%^{3,4,5,6}$, with the highest incidence noted in patients with ST elevation myocardial infarction (STEMI) receiving thrombolytic therapy. In STEMI, ventricular arrhythmias predict higher mortality. However, there is scant data regarding the risk of ventricular arrhythmias in patients with non-ST elevation myocardial infarction (NSTEMI).

The incidence of NSTEMI has nearly doubled since the introduction cardiac troponins for the diagnosis of acute myocardial infarction ${ }^{7,8,9}$. The risk of acute life-threatening arrhythmias in these cases may differ from that in patients with STEMI, and thus the level of monitoring required may be different. In most hospitals, all patients with AMI are placed in coronary care units, irrespective of the type of infarction, for continuous electrocardiographic and hemodynamic monitoring. 
Few studies have investigated the risk of malignant arrhythmias in patients with NSTEMI. A study from Europe found the rate of malignant ventricular arrhythmias in NSTEMI patients to be $2.6 \%$. The only predictor for their occurrence was found to be the white cell count at admission ${ }^{10}$. In a pooled analysis of several studies, the incidence of ventricular arrhythmias in patients with non-ST elevation acute coronary syndromes was found to be $2.1 \%$. Several predictors were identified, including hypertension, chronic obstructive lung disease, prior MI and ST changes at presentation ${ }^{11}$.

We aimed to study the incidence of life-threatening ventricular arrhythmias and their risk factors in patients with NSTEMI treated with an early invasive strategy. Our goal was to determine if it was possible to admit selected patients with NSTEMI to less monitored settings than the coronary care unit based on the overall incidence of and risk factors for ventricular arrhythmias. 


\section{Methods:}

This was a retrospective cohort study of consecutive patients with NSTEMI, as defined by the current American College of Cardiology /American Heart Association guidelines ${ }^{12}$ who underwent cardiac catheterization within 48 hours of admission, between January 2005 and July 2007. Patients who did not undergo catheterization within 48 hours were excluded to avoid including patients with non-acute coronary syndrome troponin elevations and those with NSTEMI not considered catheterization candidates due to significant comorbidities. Demographics, cardiac risk factors, vital signs on admission, Killip class on admission, blood cell counts, basic metabolic profile, peak creatine phosphokinase, peak troponin I and electrocardiogram data were collected . Medications on admission and those administered during hospital stay were extracted from charts. Left ventricular ejection fraction (LVEF) and presence of segmental wall motion abnormalities were recorded from the echocardiogram. Coronary angiography findings were recorded as one, two or three vessel disease (defined as the number of major vessels with $>70 \%$ stenosis). Involvement of the left main coronary artery was noted separately. The Thrombolysis in Myocardial Infarction (TIMI) risk scores ${ }^{12}$ were calculated. Interventions performed, either percutaneous coronary intervention or coronary artery bypass grafting, were recorded. Thirty day mortality was acquired using the Social Security Death Index records.

Sustained ventricular tachycardia (VT) was defined by the presence of a series of consecutive ectopic ventricular beats at a rate of $>100$ beats/minute lasting $>30$ seconds or lasting less than 30 seconds but producing hemodynamic compromise. Nonsustained 
ventricular tachycardia was defined as $\geq 3$ consecutive ventricular ectopic beats at a rate of $>100$ beats/minute lasting $<30$ seconds. Episodes of nonsustained VT were not included in the definition of malignant ventricular arrhythmias after myocardial infarction. Ventricular fibrillation (VF) was defined as irregular electrocardiographic waves of inconsistent shape and unidentifiable QRS complexes accompanied by hemodynamic compromise requiring defibrillation. Cases of concomitant VT and VF were categorized as VF. Sustained VT and VF were grouped together as malignant ventricular arrhythmias.

Data were analyzed using STATA 10 Software (StataCorp, College Station, TX). Categorical data were expressed as percentages and continuous data were expressed as mean \pm standard deviation (SD). Differences between the two groups were analyzed using Fisher's exact test for categorical variables and two-sample t-test with equal variances for continuous variables. A stepwise multivariable logistic regression model was used to analyze variables that were statistically significantly associated with malignant ventricular arrhythmias on univariate analysis. 


\section{Results:}

We studied 277 consecutive patients with NSTEMI treated with an early invasive strategy. Clinical characteristics are shown in Table 1. Malignant ventricular arrhythmias occurred in $21(7.6 \%)$ patients. Non-sustained ventricular tachycardia identified in the chart occurred in another $17(6.1 \%)$ patients. Sixty percent of patients with malignant ventricular arrhythmias had these events recorded within the first 48 hours of admission to the hospital. Three patients presented to the hospital with these arrhythmias. The median time for the occurrence of malignant ventricular arrhythmias was 72 hours. Twelve patients (57\% of the malignant ventricular arrhythmia group; $4.3 \%$ of the total NSTEMI patients) required defibrillation.

There were no statistically significant differences between NSTEMI patients with and without malignant ventricular arrhythmias with respect to age, hypertension, diabetes, smoking, or family history of coronary artery disease. At presentation, more patients with malignant ventricular arrhythmias had complaints of palpitations (33\% vs. $14 \%$, $\mathrm{p}=0.028$ ). The distribution of Killip classes was similar in both groups, with the majority of patients being Killip class I.

Among laboratory values, neither potassium nor magnesium levels were statistically different between the two groups. Mean values of CPK and troponin I, were significantly higher in the group with malignant ventricular arrhythmias (mean CPK; 838 vs. 362 $\mathrm{mg} / \mathrm{dL}, \mathrm{p}<0.001$, mean troponin I 19.8 vs. $9.1 \mathrm{ng} / \mathrm{mL}, \mathrm{p}=0.016)$. 
Only one patient $(5 \%)$ who developed malignant ventricular arrhythmia had a normal electrocardiogram at presentation, while $56(22 \%)$ patients who did not have ventricular arrhythmias had normal presenting electrocardiograms $(\mathrm{p}=0.045)$. The most frequent abnormality observed was T wave inversion, seen in $86 \%$ of patients with a malignant ventricular arrhythmia and $52 \%$ cases without $(\mathrm{p}=0.003)$. Thirty three percent of patients who had malignant ventricular arrhythmias had a left bundle branch block (LBBB) compared to $10 \%$ of those without $(\mathrm{p}=0.006)$. Other abnormalities, such as ST segment depression greater than $1 \mathrm{~mm}$ and Q waves, were not significantly different between groups. There was a non-significant trend of more frequent supraventricular arrhythmias in patients with malignant ventricular arrhythmias ( 29 vs.13\%, $\mathrm{p}=0.051$ ).

On echocardiography, the mean left ventricular ejection fraction was significantly lower in the group with malignant ventricular arrhythmias $(40 \pm 13 \%$ vs. $50 \pm 15 \%, p=0.003)$. A non-significant trend of more frequent regional wall motion abnormalities on echocardiography were seen in the malignant ventricular arrhythmia group (76\% vs. $56 \%, \mathrm{p}=0.053)$.

Coronary angiography revealed a similar proportion of patients with single, double or triple vessel disease in both groups. The TIMI risk score was not significantly different between groups. However the number of patients with ventricular arrhythmias undergoing coronary artery bypass grafting was significantly higher than that of patients without these arrhythmias (38\% versus $14 \%, \mathrm{p}=0.008)$. 
Medications at admission were similar in both groups, as were medications administered during hospital stay with the exception of amiodarone (Table 2). Amiodarone was used more often in patients with ventricular arrhythmias (48\% versus $6 \% ; \mathrm{p}<0.001)$. Seven patients $(33 \%)$ with malignant ventricular arrhythmias were administered lidocaine.

LVEF, LBBB on electrocardiogram, peak troponin I value, and need for urgent coronary artery bypass grafting were the variables entered in to a stepwise logistic regression analysis. Of these, LBBB and urgent coronary artery bypass grafting were found to be statistically significant predictors of patients having malignant ventricular arrhythmias (Table 3).

Thirty day mortality was significantly higher in the malignant ventricular arrhythmia group $(38 \%$ versus $3 \%, \mathrm{p}<0.001)$. When thirty-day mortality was used as an outcome variable in a multivariable logistic regression analysis using other factors associated with a higher mortality in NSTEMI patients (LVEF, peak troponin I and chronic kidney disease), ventricular arrhythmias remained significantly predictive of mortality (odds ratio $15.38,95 \%$ confidence intervals $4.31-54.96$; Table 4). Interestingly, the mortality in the $6.1 \%$ of patients with non-sustained ventricular tachycardia was intermediate at $21 \%$. 


\section{Discussion:}

The risk of life-threatening ventricular arrhythmias in patients with NSTEMI treated with an early invasive strategy was $7.6 \%$ in this study. On multivariate analysis, risk factors identified for predicting their occurrence were LBBB and need for urgent coronary artery bypass surgery. NSTEMI patients who experienced malignant arrhythmias had a significantly higher 30 day mortality compared to those who did not.

The incidence of malignant ventricular arrhythmias was higher in our study than previously reported in patients with NSTEMI ${ }^{10,11,14}$. Comparison of patient characteristics reveals that NSTEMI patients in the present inner-city hospital study had a higher incidence of cardiac risk factors, including hypertension, dyslipidemia, diabetes and family history of coronary artery disease, in addition to a higher incidence of previous myocardial infarction, as compared to the patient populations in these studies $^{10,11,14}$. In contrast, the incidence of malignant ventricular arrhythmias in the NSTEMI population studied was lower than that seen in patients with STEMI in the Global Utilization of Streptokinase and TPA for Occluded coronary arteries (GUSTO-I; $10.5 \%$ ), the Global Use of Strategies to Open occluded coronary arteries (GUSTO III; 7.3\%), and the Euro Heart Survey of Acute Coronary Syndromes (10\%) studies ${ }^{14}$.

In the present study, the median time to development of malignant ventricular arrhythmias was 72 hours, comparable to 78 hours in a pooled analysis of four randomized trials of NSTEMI patients ${ }^{11}$. Only $60 \%$ of our patients had malignant ventricular arrhythmias recorded within the first 48 hours, whereas in most other studies, 
malignant ventricular arrhythmias were recorded in 70 to $90 \%$ cases within the first 48 hours of presentation; the percentage is even higher in patients with STEMI ${ }^{10,11,14,15}$.

Traditional risk factors for coronary artery disease and previous myocardial infarction, were not found to predict malignant ventricular arrhythmias. Other studies found different factors associated with the risk of malignant ventricular arrhythmias, including hypertension, chronic obstructive pulmonary disease, previous myocardial infarctions, heart failure, cardiogenic shock, and chronic kidney disease ${ }^{11,17}$. None of these factors were consistently observed across studies, suggesting relatively weak causality.

Although low serum potassium and magnesium levels have been shown to be associated with an increased incidence of ventricular arrhythmias, there was no correlation in this study. This may be because we considered only the admission values for analysis, and it is likely that NSTEMI patients with hypokalemia and hypomagnesemia were aggressively treated.

NSTEMI patients with higher CPK and troponin values and lower left ventricular ejection fractions (factors suggesting a larger infarct) were more likely to have malignant ventricular arrhythmias. This is similar to studies in STEMI patients that have demonstrated a higher likelihood of developing ventricular arrhythmias with larger infarcts $^{4,17,18}$. Larger infarctions are associated with early left ventricular dilatation and remodeling due to ventricular stretching and electromechanical feedback, thus producing a substrate capable of developing reentrant circuits for arrhythmia genesis ${ }^{19,20}$. 
Patients with LBBB on electrocardiogram were more likely to develop ventricular arrhythmias, similar to findings from other studies ${ }^{21,22}$. The incidence of LBBB in patients with ventricular arrhythmias was higher in our study at 21\% as opposed to 5-7 \% in other studies ${ }^{10}$. This may be related to the higher prevalence of risk factors in our patients. The blocked bundle branch can provide a reentry circuit which, along with local ionic changes induced by ischemia and functional autonomic denervation, can lead to genesis of ventricular arrhythmias ${ }^{23,24}$.

The TIMI risk score is widely used to risk-stratify patients with non-ST elevation acute coronary syndromes. In the present study, the mean TIMI scores did not differ between groups. This is not surprising given that none of the components of the TIMI score were significantly predictive of malignant ventricular arrhythmias in this study. Other studies have found the TIMI score to predict mortality but not the risk of arrhythmias ${ }^{10}$.

Need for urgent coronary artery bypass grafting was found to be significantly associated with malignant ventricular arrhythmias. Oxygen-derived free radicals and transient calcium overload play important pathologic roles in arrhythmogenesis after cardiac surgery $^{25}$. Although supraventricular arrhythmias and ventricular extrasystoles are far more common after coronary artery bypass grafting ${ }^{26}$, studies have reported a higher incidence of malignant ventricular arrhythmias ${ }^{27,28}$. Potential reasons why malignant ventricular arrhythmias are more frequent in these patients could be that they were 
revascularized later than those undergoing percutaneous coronary intervention, and may have had greater amounts of ischemic myocardium.

To conclude, the significant risk of malignant ventricular arrhythmias in NSTEMI found in the present study supports the current practice of monitoring these patients in the coronary care unit early in the course of their illness. Since mortality associated with these arrhythmias is high, we need to identify factors predictive of their development such as those found in our study. Prospective studies to develop risk scores predicting ventricular arrhythmias could provide triage algorithms for determining levels of care/monitoring during hospitalization. 


\section{References:}

1. Janse MJ; Wit AL. Electrophysiological mechanisms of ventricular arrhythmias resulting from myocardial ischemia and infarction. Physiol Rev 1989 Oct;69(4):1049-169.

2. Tansey MJ; Opie LH. Relation between plasma free fatty acids and arrhythmias within the first twelve hours of acute myocardial infarction. Lancet 1983 Aug 20;2(8347):419-22.

3. M. Eldar, Z. Sievner and U. Goldbourt et al. Primary ventricular tachycardia in acute myocardial infarction: clinical characteristics and mortality: The SPRINT Study Group. Ann Intern Med 1992; 117: 31-36.

4. S.M. Al-Khatib, A.L. Stebbins and R.M. Califf et al. Sustained ventricular arrhythmias and mortality among patients with acute myocardial infarction: results from the GUSTO-III trial. Am Heart J 2003;145:515-21.

5. R.H. Mehta, K.J. Harjai and L. Grines et al. Sustained ventricular tachycardia or fibrillation in the cardiac catheterization laboratory among patients receiving primary percutaneous coronary intervention: incidence, predictors, and outcomes, $J$ Am Coll Cardiol 2004;43:1765-72.

6. Henkel DM, Witt BJ, Gersh BJ, et al. Ventricular arrhythmias after acute myocardial infarction: a 20-year community study. Am Heart J. 2006;151:806812.

7. Myocardial infarction redefined-A consensus document of The Joint European Society of Cardiology/American College of Cardiology Committee for the Redefinition of Myocardial Infarction. Eur Heart J 20000;21:1502-13.

8. Pell JP, Simpson E, Rodger JC, Finlayson A, Clark D, Anderson J, Pell ACH. Impact of changing diagnostic criteria on incidence, management, and outcome of acute myocardial infarction: retrospective cohort study. BMJ 2000;326:134-5.

9. Kontos MC, Fritz LM, Anderson FP, Tatum JL, Ornato JP, Jesse RL. Impact of the troponin standard on the prevalence of acute myocardial infarction. Am Heart $J$ 2003;146:446-52.

10. Rahimi K, Watslawek S, Thiele $\mathrm{H}$ et al. Incidence, time course, and predictors of early malignant ventricular arrhythmias after non-ST-segment elevation myocardial infarction in patients with early invasive treatment. Eur Heart J 2006;27(14):1706-11.

11. Al-Khatib SM, Granger CB, Huang Y et al. Sustained ventricular arrhythmias among patients with acute coronary syndromes with no ST-segment elevation: incidence, predictors, and outcomes. Circulationjavascript:AL_get(this, 'jour', 'Circulation.'); 2002;106(3):309-12.

12. Anderson JL, Adams CD, Antman EM, Bridges ER etal. ACC/AHA 2007 Guidelines for the Management of Patients With Unstable Angina/Non-STElevation Myocardial Infarction. A Report of the American College of Cardiology/American Heart Association Task Force on Practice Guidelines (Writing Committee to Revise the 2002 Guidelines for the Management of Patients With Unstable Angina/Non-ST-Elevation Myocardial Infarction) Developed in Collaboration with the American College of Emergency Physicians, the Society for Cardiovascular Angiography and Interventions, and the Society of 
Thoracic Surgeons Endorsed by the American Association of Cardiovascular and Pulmonary Rehabilitation and the Society for Academic Emergency Medicine $J$ Am Coll Cardiol, 2007; 50:1-157.

13. Antman EM, Cohen M, Bernink PJ, McCabe CH, Horacek T, Papuchis G, Mautner B, Corbalan R, Radley D, Braunwald E. The TIMI risk score for unstable angina/non-ST elevation MI: a method for prognostication and therapeutic decision making. JAMA 2000;284:835-842.

14. Hasdai D, Behar S, Wallentin L, Danchin N, Gitt AK, Boersma E, Fioretti PM, Simoons ML, Battler A. A prospective survey of the characteristics, treatments and outcomes of patients with acute coronary syndromes in Europe and the Mediterranean basin; the Euro Heart Survey of Acute Coronary Syndromes (Euro Heart Survey ACS). Eur Heart J 2000; 23:1190-1201.

15. Newby LK, Hasselblad V, Armstrong PW, Van de WF, Mark DB, White HD, Topol EJ, Califf RM. Time-based risk assessment after myocardial infarction. Implications for timing of discharge and applications to medical decision-making. Eur Heart J 2003;24:182-9.

16. Henkel DM, Witt BJ, Gersh BJ, Jacobsen SJ, Weston SA, Meverden RA, Roger VL. Ventricular arrhythmias after acute myocardial infarction: a 20-year community study. Am Heart J. 2006;151(4):806-12

17. Piccini JP, Berger JS, Brown DL. Early sustained ventricular arrhythmias complicating acute myocardial infarction. Am J Med 2008; 121(9):797-804.

18. Newby KH, Thompson T, Stebbins A, Topol EJ, Califf RM, Natale A. Sustained ventricular arrhythmias in patients receiving thrombolytic therapy: incidence and outcomes. The GUSTO Investigators. Circulation. 1998 Dec 8;98(23):2567-73.

19. Hansen DE; Craig CS; Hondeghem LM. Stretch-induced arrhythmias in the isolated canine ventricle. Evidence for the importance of mechanoelectrical feedback. Circulation 1990 Mar;81(3):1094-105.

20. Popovic AD; Neskovic AN; Pavlovski K; Marinkovic J; Babic R; Bojic M; Tan M; Thomas JD. Association of ventricular arrhythmias with left ventricular remodelling after myocardial infarction. Heart 1997 May;77(5):423-7.

21. Goldberg RJ, Yarzebski J, Spencer FA, Zevallos JC, Lessard D, Gore JM. Thirtyyear trends (1975-2005) in the magnitude, patient characteristics, and hospital outcomes of patients with acute myocardial infarction complicated by ventricular fibrillation. Am J Cardiol. 2008 Dec 15;102(12):1595-601.

22. Dissmann R, Kamke W, Reibis R, Herbstleb J, Wegscheider K, Völler H. Prognostic impact of left bundle-branch block in the early stable phase after acute myocardial infarction. Int J Cardiol. 2008 Nov 28;130(3):438-43.

23. Fisch Gr, Zipes DP, Fisch C. Bundle branch Block and Sudden Death. Prog Cardiovasc Dis 1980; 23:187-224.

24. Gann D, Balachandran PK, El-Sherif N, Samet P. Prognostic significance of chronic versus acute bundle branch block in acute myocardial infarction. Chest 1975; 67:298-303.

25. Bril A. Cellular mechanism of cardiac arrhythmias in the ischemic and reperfused heart. EXS 1996;76:135-153.

26. Ormerod O.J., McGregor C.G., Stone D.L., Wisbey C., Petch M.C. Arrhythmias after coronary bypass surgery. Br Heart J 1984;51:618-21. 
27. Steinberg J.S., Gaur A., Sciacca R., Tan E. New-onset sustained ventricular tachycardia after cardiac surgery. Circulation 1999;99:903-8

28. Wu ZK, Iivianen T, Pehkonen E, Laurikka J, Tarkka MR. Perioperative and postoperative arrhythmia in three-vessel coronary artery disease patients and antiarrhythmic effects of ischemic preconditioning. Eur J Cardiothorac Surg 2003 Apr;23(4):578-84. 
Table 1: Clinical characteristics of the two NSTEMI groups

\begin{tabular}{|c|c|c|c|}
\hline Patient characteristic & $\begin{array}{l}\text { With VT/ VF } \\
\quad(n=21)\end{array}$ & $\begin{array}{l}\text { Without VT/VF } \\
\qquad(\mathrm{n}=256)\end{array}$ & $\mathrm{P}$ value \\
\hline Age $($ mean $\pm \mathrm{SD})$ & $63.5 \pm 0.8$ & $66.3 \pm 2.8$ & 0.816 \\
\hline \multicolumn{4}{|l|}{ Gender } \\
\hline Male & $9(42.8 \%)$ & $134(52.3 \%)$ & 0.271 \\
\hline Female & $12(57.1 \%)$ & $122(47.7 \%)$ & \\
\hline \multicolumn{4}{|l|}{ Race } \\
\hline Caucasian & $4(19.1 \%)$ & $65(25.4 \%)$ & 0.268 \\
\hline African-American & $16(76.2 \%)$ & $154(60.2 \%)$ & \\
\hline Hispanic & $0(0.0 \%)$ & $28(10.9 \%)$ & \\
\hline Others & $1(4.8 \%)$ & $9(3.5 \%)$ & \\
\hline \multicolumn{4}{|l|}{ Past Medical History } \\
\hline Hypertension & $18(85.7 \%)$ & $210(82.0 \%)$ & 0.472 \\
\hline Diabetes Mellitus & $7(33.3 \%)$ & $109(42.6 \%)$ & 0.279 \\
\hline Dyslipidemia & $13(61.9 \%)$ & $141(55.1 \%)$ & 0.356 \\
\hline Coronary Artery Disease & $12(57.1 \%)$ & $121(47.3 \%)$ & 0.260 \\
\hline Myocardial Infarction & $9(42.9 \%)$ & $12(57.1 \%)$ & 0.549 \\
\hline Congestive Heart Failure & $6(28.6 \%)$ & $35(13.7 \%)$ & 0.071 \\
\hline Arrhythmias & $3(14.3 \%)$ & $20(7.8 \%)$ & 0.347 \\
\hline Chronic kidney disease & $7(33.3 \%)$ & $86(33.6 \%)$ & 0.594 \\
\hline Prior angioplasty & $5(23.8 \%)$ & $64(25.0 \%)$ & 0.571 \\
\hline $\begin{array}{l}\text { Prior coronary artery bypass } \\
\text { grafting }\end{array}$ & $1(4.8 \%)$ & $37(14.5 \%)$ & 0.184 \\
\hline Obesity & $2(9.5 \%)$ & $55(21.5 \%)$ & 0.152 \\
\hline Smoking & $11(52.4 \%)$ & $138(53.9 \%)$ & 0.535 \\
\hline $\begin{array}{l}\text { Chronic obstructive pulmonary } \\
\text { disease }\end{array}$ & $1(4.7 \%)$ & $34(13.3 \%)$ & 0.491 \\
\hline \multicolumn{4}{|l|}{ Chief Complaints } \\
\hline Chest Pain & $16(76.1 \%)$ & $220(85.9 \%)$ & 0.182 \\
\hline Dyspnea & $10(47.6 \%)$ & $139(54.3 \%)$ & 0.357 \\
\hline Palpitations & $7(33.3 \%)$ & $36(14.1 \%)$ & 0.028 \\
\hline Systolic Blood Pressure (mm Hg) & $137 \pm 31$ & $143 \pm 28$ & 0.151 \\
\hline Diastolic Blood Pressure(mm Hg) & $77 \pm 23$ & $78 \pm 17$ & 0.345 \\
\hline
\end{tabular}




\begin{tabular}{|c|c|c|c|}
\hline \multicolumn{4}{|l|}{ Laboratory values } \\
\hline Hemoglobin & $11.4 \pm 0.3$ & $12.1 \pm 0.1$ & 0.052 \\
\hline White cell count & $9.9 \pm 0.9$ & $8.7 \pm 0.2$ & 0.104 \\
\hline Creatinine & $1.4 \pm 0.7$ & $1.6 \pm 2.2$ & 0.289 \\
\hline Potassium & $4.4 \pm 0.1$ & $4.3 \pm 0.1$ & 0.745 \\
\hline Magnesium & $2.1 \pm 0.1$ & $1.9 \pm 0.0$ & 0.949 \\
\hline Creatine Phosphokinase & $838.3 \pm 939.2$ & $361.9 \pm 499.6$ & $<0.001$ \\
\hline Troponin I (peak) & $19.8 \pm 29.2$ & $9.1 \pm 20.9$ & 0.016 \\
\hline TIMI Score (mean) & 5 & 4 & 0.085 \\
\hline $\begin{array}{l}\text { Killip Class on Admission } \\
\text { I } \\
\text { II } \\
\text { III } \\
\text { IV }\end{array}$ & $\begin{array}{l}17(81.0 \%) \\
1(4.8 \%) \\
2(9.5 \%) \\
1(4.8 \%)\end{array}$ & $\begin{array}{l}224(87.5 \%) \\
18(7.0 \%) \\
12(4.7 \%) \\
2(0.8 \%)\end{array}$ & 0.185 \\
\hline $\begin{array}{l}\text { Electrocardiographic changes } \\
\text { Normal EKG } \\
\text { ST depression }>1 \mathrm{~mm} \\
\text { T wave inversion } \\
\text { Q wave } \\
\text { Left bundle branch block } \\
\text { Supraventricular arrhythmia }\end{array}$ & $\begin{array}{c}1(4.8 \%) \\
9(42.9 \%) \\
18(85.7 \%) \\
3(14.3 \%) \\
7(33.3 \%) \\
6(28.6 \%)\end{array}$ & $\begin{array}{c}56(21.9 \%) \\
98(38.3 \%) \\
134(52.3 \%) \\
19(7.4 \%) \\
26(10.2 \%) \\
32(12.5 \%)\end{array}$ & $\begin{array}{l}\mathbf{0 . 0 4 5} \\
0.423 \\
\mathbf{0 . 0 0 3} \\
0.226 \\
\mathbf{0 . 0 0 6} \\
\mathbf{0 . 0 5 1}\end{array}$ \\
\hline $\begin{array}{l}\text { Echocardiographic parameters } \\
\text { Left Ventricular Ejection }\end{array}$ & $40.0 \pm 12.9$ & $49.9 \pm 14.7$ & 0.003 \\
\hline $\begin{array}{l}\text { Fraction } \\
\text { Segmental Wall Motion } \\
\text { Abnormailty }\end{array}$ & $16(76.3 \%)$ & $141(55.7 \%)$ & 0.053 \\
\hline Presence of NSVT & $3(14.3 \%)$ & $14(5.5 \%)$ & 0.128 \\
\hline \multicolumn{4}{|l|}{ Cardiac Catheterization } \\
\hline Normal angiogram & $1(4.8 \%)$ & $22(8.6 \%)$ & 0.462 \\
\hline One-vessel disease & $5(23.8 \%)$ & $64(25.0 \%)$ & 0.571 \\
\hline Two-vessel disease & $6(28.6 \%)$ & $66(25.8 \%)$ & 0.477 \\
\hline Three-vessel disease & $9(42.9 \%)$ & $104(40.6 \%)$ & 0.507 \\
\hline Intervention & $16(17.2 \%)$ & $170(66.4 \%)$ & 0.254 \\
\hline PCI with stent placement & $8(38.1 \%)$ & $139(54.3 \%)$ & 0.115 \\
\hline Coronary artery bypass grafting & $8(38.1 \%)$ & $35(13.7 \%)$ & 0.008 \\
\hline Mortality at 30 days & $8(38.1 \%)$ & $8(3.1 \%)$ & $<0.001$ \\
\hline
\end{tabular}


Table 2: Medical treatment of patients in the two groups

\begin{tabular}{l|rcc}
\hline Medication & $\begin{array}{c}\text { With VT/VF } \\
(\mathrm{n}=21)\end{array}$ & $\begin{array}{c}\text { Without VT/VF } \\
(\mathrm{n}=256)\end{array}$ & P value \\
\hline Medications at admission & $12(57.1 \%)$ & $123(48.1 \%)$ & 0.283 \\
Aspirin & $5(23.8 \%)$ & $62(24.2 \%)$ & 0.602 \\
Clopidogrel & $9(42.9 \%)$ & $127(49.6 \%)$ & 0.652 \\
Beta-blocker & $13(61.9 \%)$ & $123(48.0 \%)$ & 0.261 \\
ACE-inhibitor & $8(38.0 \%)$ & $62(24.2 \%)$ & 0.191 \\
Calcium-channel & $12(57.1 \%)$ & $143(55.9 \%)$ & 0.549 \\
blocker & $7(33.3 \%)$ & $84(32.8 \%)$ & 0.567 \\
Statins & $4(19.1 \%)$ & $55(21.5 \%)$ & 0.524 \\
Diuretics & & & \\
Nitrates & & & \\
& $21(100 \%)$ & $251(98.1 \%)$ & 0.672 \\
Acute medications & $12(57.1 \%)$ & $183(71.5 \%)$ & 0.129 \\
Aspirin & $7(33.3 \%)$ & $88(34.4 \%)$ & 0.565 \\
Clopidogrel & $20(95.2 \%)$ & $249(97.3 \%)$ & 0.472 \\
GpIIb/IIIa antagonist & $19(90.5 \%)$ & $241(94.1 \%)$ & 0.376 \\
Heparin & $10(47.6 \%)$ & $14(5.5 \%)$ & $<0.001$ \\
Beta-blocker & $7(33.3 \%)$ & 0 & ---- \\
Amiodarone & & & \\
Lidocaine & & &
\end{tabular}


Table 3: Multivariable Regression Analysis for Malignant Arrhythmias

\begin{tabular}{l|ll}
\hline & Odds Ratio (95\% CI) & P Value \\
\hline Troponin I value & $1.01(0.99-1.03)$ & 0.098 \\
Left Bundle Branch Block & $3.66(1.28-10.44)$ & 0.015 \\
Left Ventricular Ejection Fraction & $0.96(0.93-0.99)$ & 0.023 \\
Coronary Artery Bypass Grafting & $3.99(1.46-10.91)$ & 0.007 \\
\hline
\end{tabular}


Table 4: Multivariable Regression Analysis for Thirty-Day Mortality

\begin{tabular}{l|lc}
\hline & Odds Ratio (95\% CI) & P Value \\
\hline Ventricular arrhythmias & $15.38(4.31-54.96)$ & $<0.001$ \\
Troponin I value & $1.02(1.00-1.04)$ & 0.017 \\
Left Ventricular Ejection Fraction & $0.96(0.92-0.99)$ & 0.048 \\
Chronic Kidney Disease & $2.63(0.77-8.99)$ & 0.123 \\
\hline
\end{tabular}

